\title{
Advances in Thoracoscopy: 100 Years since Jacobaeus
}

\author{
Pyng Lee $^{a}$ Praveen N. Mathur ${ }^{b}$ Henri G. Colt ${ }^{c}$ \\ a Department of Respiratory and Critical Care Medicine, Singapore General Hospital, Singapore, Singapore; \\ Divisions of Pulmonary and Critical Care Medicine, ${ }^{b}$ Medical University of Indiana, Indianapolis, Ind., and \\ 'University of California, Irvine Medical Center, Orange, Calif., USA
}

\section{Key Words}

Flexible-rigid pleuroscope $\cdot$ Jacobaeus, Hans Christian •

Pleura - Pleuroscopy $\cdot$ Thoracoscopy, medical ·

Video-assisted thoracic surgery

\begin{abstract}
Thoracoscopy provides the physician a window into the pleural space, and enables the biopsy of the parietal pleura under direct visual guidance, chest tube placement and pleurodesis for recurrent pleural effusions or pneumothoraces in selected patients. In this review, we discuss the advances that have been achieved in thoracoscopy since its inception more than a century ago.
\end{abstract}

Copyright $\odot 2010$ S. Karger AG, Basel

\section{Introduction}

Thoracoscopy, medical thoracoscopy, pleuroscopy and video-assisted thoracic surgery (VATS) are terms used to describe minimally invasive procedures that provide the physician a window into the pleural space. Difficulties associated with labeling these procedures as VATS, medical thoracoscopy or pleuroscopy are readily apparent since they are all based on thoracoscopy and differ only in the approach to anesthesia.

\section{KARGER}

Fax +4161306 1234 E-Mail karger@karger.ch www.karger.com
(C) 2010 S. Karger AG, Basel 0025-7931/10/0793-0177\$26.00/0

Accessible online at: www.karger.com/res
VATS refers to a thoracoscopic procedure performed in the operating room using single-lung ventilation with double-lumen endotracheal intubation and various disposable instruments. Technically, any thoracoscopic procedure that includes parietal pleural biopsies, drainage of pleural effusions or empyema, and pleurodesis performed with the patient under general anesthesia and single-lung ventilation can be called VATS. However, VATS is usually performed for stapled lung biopsy, resection of pulmonary nodules, lobectomy, pneumonectomy, esophagectomy or pericardial window (table 1$)[1,2]$.

Medical thoracoscopy, on the other hand, refers to thoracoscopy that is performed in an endoscopy suite or operating room with the patient under conscious sedation and local anesthesia. Increasingly, these procedures are being performed by nonsurgeon pulmonologists. Many experts prefer pleuroscopy over medical thoracoscopy as the term pleuroscopy appears most appropriate when interventions are limited to diagnosing pleural pathology such as pleural effusions or pleural carcinomatosis, talc pleurodesis and chest tube placement under direct visual guidance [3]. Some practitioners in Europe also perform pleuroscopic sympathectomies in patients with hyperhydrosis [4].

Previous article in this series: 1. Herth FJF, Gompelmann D, Ernst A, Eberhardt R: Endoscopic lung volume reduction. Respiration 2010;79:5-13. 
Table 1. VATS versus medical thoracoscopy (pleuroscopy)

\begin{tabular}{lll}
\hline Procedure & VATS & Medical thoracoscopy (pleuroscopy) \\
\hline Where & Operating room & Endoscopy suite or operating room \\
\hline Who & Surgeons & Trained pulmonologists \\
\hline Anesthesia & $\begin{array}{l}\text { General anesthesia } \\
\text { Double-lumen endotracheal intubation } \\
\text { Single-lung ventilation }\end{array}$ & $\begin{array}{l}\text { Local anesthesia } \\
\text { Conscious sedation }\end{array}$ \\
\hline Indications & $\begin{array}{l}\text { Stapled lung biopsy, pulmonary nodule resection, lobectomy, } \\
\text { pneumonectomy, pericardial window, esophagectomy, parietal } \\
\text { pleural biopsy, drainage of pleural effusion or empyema }\end{array}$ & $\begin{array}{l}\text { Pleural cavity exploration, parietal pleura } \\
\text { biopsy, pleurodesis, chest tube under direct } \\
\text { visualization }\end{array}$ \\
\hline
\end{tabular}

Thoracoscopy was first conceived in a report dated 1866 that documented the first endoscopic examination of the pleural space by Richard Cruise in an 11-year-old girl with empyema [5]. Thoracoscopy did not gain widespread use until 1910 when Hans Christian Jacobaeus published his technique also known as the Jacobaeus operation [6]. In this procedure, he created a pneumothorax by severing adhesions using galvanocautery that collapsed the underlying lung, and allowed safe entry as well as unobstructed examination of the pleural space. He advocated thoracoscopic-guided biopsies for pleural effusions of indeterminate etiology, and applied thoracoscopy both as a diagnostic and therapeutic tool [7].

\section{Equipment}

\section{Rigid Instruments}

Since the first description of the Jacobaeus operation, rigid endoscopic instruments such as stainless-steel trocars and telescopes have been pivotal in the technique [4, $8,9]$. Trocars come in different sizes (diameter, 5-13 mm), and are made of disposable plastic or reusable stainless steel. These trocars have changed little over time but operators have increasingly moved to disposable, plastic, ribbed trocars with either plastic or steel inner cannulas. Rigid telescopes have different angles of vision. Thoracoscopy performed by rigid endoscopic equipment requires a cold (xenon) light source, an endoscopic camera attached to the eyepiece of the telescope, video monitor and recorder (fig. 1). The $0^{\circ}$ telescope is useful for direct viewing while the oblique $\left(30\right.$ or $\left.50^{\circ}\right)$ and periscope $\left(90^{\circ}\right)$ telescopes offer panoramic view of the pleural cavity. Selection of the optimal size of a trocar and telescope de- pends on operator preferences and patient characteristics. A large trocar that accommodates a larger telescope with better optics improves the quality of exploration, but compression of the intercostal nerve during manipulation of the trocar may cause greater discomfort especially if the procedure is performed under local anesthesia and conscious sedation. We prefer the $7-\mathrm{mm}$ trocar, the direct viewing $\left(0^{\circ}\right) 4$ - or 7-mm telescope, and the 5-mm optical forceps that allows pleural biopsy without the need for second puncture.

Smaller telescopes and instruments have also been used. Tassi and Marchetti [10] reported excellent views of the pleural space using a $3.3-\mathrm{mm}$ telescope for a group of patients with small loculated pleural effusions that were inaccessible to standard-sized instruments. Two $3.8-\mathrm{mm}$ trocars were used, one for the $3.3-\mathrm{mm}$ telescope and the other for the 3-mm biopsy forceps. The reported diagnostic yield of $93.4 \%$ was comparable with that achieved using conventional 5-mm biopsy forceps.

\section{Flexible-Rigid Pleuroscope}

A single 1-cm skin incision that accommodates a disposable $8-\mathrm{mm}$ (inner diameter) flexible trocar should suffice for the flexible-rigid pleuroscope. The flexiblerigid pleuroscope (model LTF 160 or 240; Olympus, Tokyo, Japan) is fashioned like the flexible bronchoscope (fig. 2a). It consists of a handle and a shaft that measures $7 \mathrm{~mm}$ in outer diameter and $27 \mathrm{~cm}$ in length. The shaft is made up of a $22-\mathrm{cm}$ proximal rigid portion and a $5-\mathrm{cm}$ flexible distal end. The flexible tip is movable by a lever on the handle, which allows 2-way angulation $160^{\circ}$ up and $130^{\circ}$ down. It has a $2.8-\mathrm{mm}$ working channel that accommodates biopsy forceps, needles and other accessories, and is compatible with various electrosurgical and 
Fig. 1. Rigid trocars, telescopes and accessories.
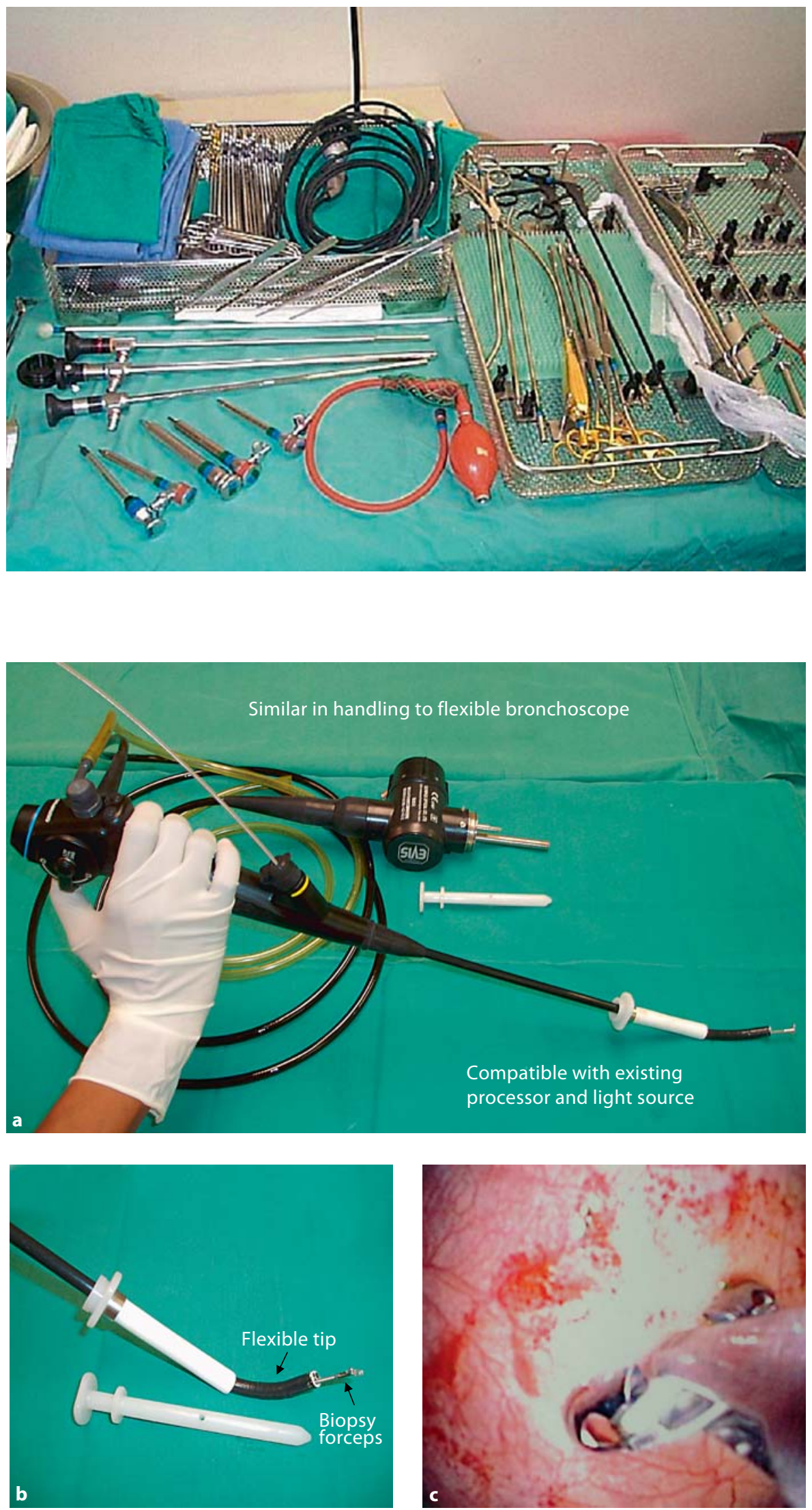

Fig. 2. a Flexible-rigid pleuroscope (LTF 160, Olympus). b Pleuroscope within flexible trocar and flexible biopsy forceps (trocar: outer and inner diameters $=10$ and $8 \mathrm{~mm}$, respectively). c Biopsy of parietal pleura with flexible forceps.

Advances in Thoracoscopy since Jacobaeus 
laser procedures (fig. 2b). The LTF 160 model also allows autoclaving [11]. A notable advantage of the flexible-rigid pleuroscope over rigid instruments is its easy interface with existing processors (CV-160 or CLV-U40) and light sources (CV-240, EVIS-100 or 140, EVIS EXERA-145 or 160) made by the manufacturer for flexible bronchoscopy or gastrointestinal endoscopy, which are available in most endoscopy units at no additional costs $[3,12]$.

\section{Indications and Contraindications for Thoracoscopy}

Although the only absolute contraindication to thoracoscopy is the lack of pleural space due to adhesions, it can be overcome by enlarging the skin incision or digitally dissecting the lung from the chest wall. As thoracoscopy is performed under conscious sedation in a spontaneously breathing patient with partial or near-total lung collapse, these patients must not have respiratory insufficiency requiring mechanical ventilation, intolerable hypoxemia unrelated to pleural effusion, unstable cardiovascular status, bleeding diathesis, refractory cough or allergy to the medications used.

\section{Patient Preparation}

A detailed history and physical examination are vital components of any pre-operative evaluation. Chest radiograph, decubitus film, ultrasonography and CT scan aid in the selection of an appropriate entry site. In preparation of a patient with pleural effusion, approximately $200-300 \mathrm{ml}$ of fluid are aspirated from the pleural cavity using a needle, angiocatheter, arrow thoracentesis catheter or Boutin pleural puncture needle. Pneumothorax is induced by the opening of needle to air until a stable equilibrium is reached. This allows the lung to collapse away from the chest wall, and creates a space for trocar insertion. Conversely, the operator may choose to do the procedure directly as he or she enters a fluid-filled pleural space, or with the aid of ultrasonography [13].

\section{Anesthesia}

A combination of benzodiazepines (midazolam) and opioids (Demerol, fentanyl or morphine) usually suffices to achieve analgesia and sedation [14]. Meticulous care towards administration of local anesthesia to the four layers, epidermis, aponeurosis, intercostal muscles and

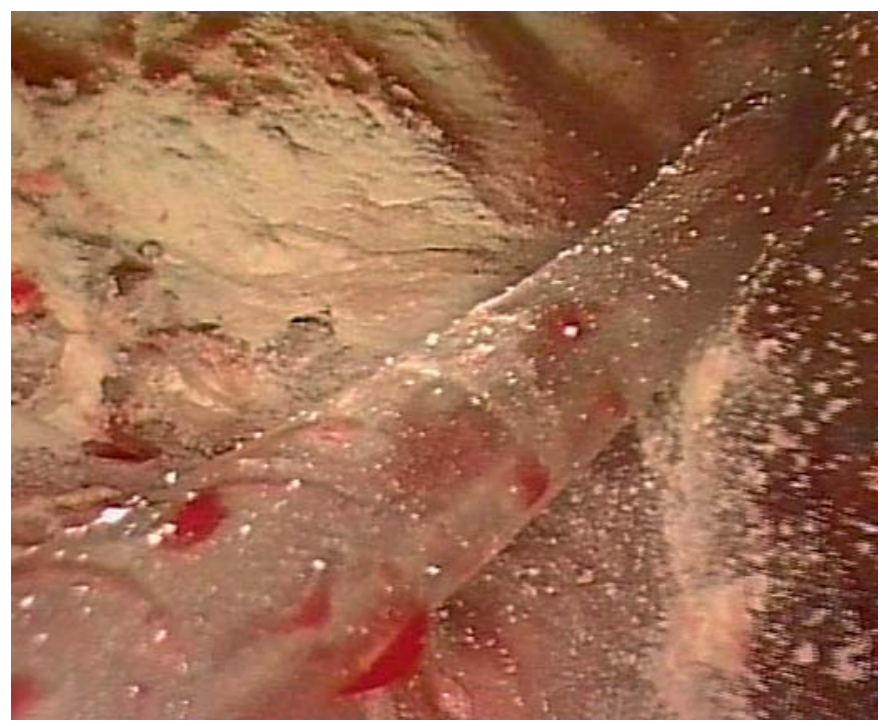

Fig. 3. Thoracoscopic talc poudrage.

parietal pleura at the entry site, assures patient comfort during manipulation of the thoracoscope [15]. There is a trend in recent years towards greater utilization of propofol to enhance patient comfort especially if talc poudrage is planned, however propofol use requires monitoring by anesthesiologists in many countries [16]. We have successfully performed thoracoscopic talc poudrage for pneumothoraces and malignant effusions using benzodiazepines (midazolam) and opioids (Demerol and fentanyl), and anesthetizing the pleura prior to talc poudrage with $250 \mathrm{mg} 1 \%$ lidocaine administered via spray catheter (fig. 3). Pain control was satisfactory [17]. Pre-operative anesthesia should be individualized by taking into consideration the patient's general condition and expectations as well as by weighing the advantages and disadvantages of various methods for pain control.

\section{Technique}

The patient is first placed in lateral decubitus position with the affected side up and the arm above the head. Patient's vital parameters, ECG, blood pressure and oxygenation by means of pulse oximetry are monitored. Single-port access sited between the 4th and 7th intercostal spaces of the chest wall and along the midaxillary line using a 5- to $10-\mathrm{mm}$ trocar usually suffices for diagnostic pleuroscopy, guided pleural biopsy and 
talc poudrage. A second port might be necessary to facilitate adhesiolysis, drainage of complex loculated fluid collections, lung biopsy or sampling of pathological lesions located around the first entry site. Similarly, double-port access may be necessary to evaluate the pleural space completely when the rigid telescope is used especially if the posterior and mediastinal aspects of the hemithorax are inaccessible due to partial collapse of the lung or when the lung parenchyma is adherent to the chest wall. A single-port access often suffices for thoracoscopy performed with the flexible-rigid pleuroscope as it overcomes limited view by easy maneuverability of its nimble tip around adhesions $[11,12,17,18]$. At the end of diagnostic thoracoscopy, a chest tube is inserted and air is aspirated. The tube can be removed as soon as the lung has reexpanded, and the patient returns home after a brief observation in a recovery area. If talc pleurodesis or lung biopsy is performed, the patient requires hospitalization for a period of monitoring and chest tube drainage.

\section{Thoracoscopic-Guided Biopsy of the Parietal Pleura}

Biopsy of the parietal pleura should be performed over a rib to avoid the neurovascular bundle. This can be achieved with the rigid optical or flexible forceps. The forceps is first used to probe the rib to feel the hard undersurface, followed by the grasping of the parietal pleura overlying it, and removing the pleura with a long tearing rather than a 'grab-and-pull' motion. Specimens that are obtained with the rigid forceps are significantly larger than those with Abrams or Cope's needle. Biopsies with the flexible-rigid pleuroscope are small since they are limited by the size of the flexible forceps, which in turn depends on the diameter of the working channel (fig. 2c). The flexible forceps also lacks mechanical strength in obtaining pleural specimens of sufficient depth, a major factor that affects the yield when mesothelioma is suspected. This technical hitch can be overcome by taking multiple biopsies (range, 5-10) of abnormal areas as well as several 'bites' of the same area to obtain tissue of sufficient depth.

\section{Electrosurgical Biopsy of Parietal Pleura}

Electrocautery has also been incorporated into biopsy with flexible forceps to enhance its yield. Full thickness parietal pleural biopsies could be obtained using the insulated tip (IT) diathermic knife during flexible-rigid pleuroscopy, and reported diagnostic yields were $85 \%$ with IT knife and $60 \%$ with flexible forceps. The IT knife was notably useful when smooth thickened lesions were encountered of which nearly half were malignant mesothelioma [19].

\section{Management of Hemorrhage}

The principal danger is hemorrhage from inadvertent biopsy of an intercostal vessel. Immediate external application of finger pressure at the site of bleeding in the intercostal space is the first intervention. During this time, another incision is made to provide additional access to the pleural cavity. The physician can use two separate entry sites to examine the bleeding area while cauterizing the tissues. Direct pressure can also be applied from the inside, using a gauze peanut mounted on a forceps. Reexpansion of the lung by connecting a chest tube to underwater seal aids in providing tamponade to the bleeding site. Very rarely, if bleeding does not abate with the above measures, the thoracic surgeon might have to ligate the bleeding vessels with endoclips, enlarge the incision and even consider thoracotomy.

\section{Thoracoscopic Talc Poudrage}

Chemical pleurodesis plays an integral role in the management of malignant effusions as most recur unless the primary tumor is chemosensitive. Similarly, one of the primary goals in secondary spontaneous pneumothorax management is recurrence prevention. Chemical pleurodesis can be performed via instillation of sclerosants through intercostal tubes or small-bore catheters or talc poudrage during thoracoscopy. The Cochrane database systematic review of pleurodesis for malignant effusions, which includes 36 randomized controlled trials consisting of 1,499 patients, supports talc as the sclerosant of choice and thoracoscopic talc poudrage as the preferred technique that should be considered for all patients with good performance status (fig. 3) [20]. Thoracoscopic talc poudrage can be performed following fluid aspiration and pleural biopsy. Various delivery devices are available, such as talc spray atomizer, bulb syringe and spray catheter, and introduced through the working channel of the flexible-rigid pleuroscope.

\section{Complications}

Mortality from conventional thoracoscopy using rigid instruments ranges between 0.09 and $0.24 \%$ [21, 22], which is comparable to that associated with bronchoscopic transbronchial lung biopsy, and its complications are listed in table 2. 
Table 2. Complications of thoracoscopy

Prolonged air leak

Hemorrhage

Subcutaneous emphysema

Postoperative fever

Empyema

Wound infection

Cardiac arrhythmias

Hypotension

Seeding of chest wall from mesothelioma

Complications with the flexible-rigid pleuroscope on the other hand are rare. In fact, it has been shown to be very safe when performed by pulmonologists trained in conventional thoracoscopy $[11,18]$. We reported our safety and outcome results in 51 patients with indeterminate pleural effusions who underwent flexible-rigid pleuroscopy. No morbidity or mortality was observed [18], however studies of complication rates involve procedures performed by specialists and may not reflect circumstances with less-experienced physicians. The need for adequate and satisfactory training cannot be overemphasized. Table 3 describes the type of patient suitable for rigid or flexible-rigid thoracoscopy.

\section{Clinical Applications for Thoracoscopy}

\section{Pleural Effusion of Unknown Etiology}

The first step towards investigating pleural effusion is thoracentesis. More than half of exudative effusions are due to malignancy [23], and although pleural fluid cytology is the simplest definitive method, its diagnostic yield depends on the extent of disease and nature of the primary malignancy [24]. Cytologic examination of the pleural fluid may be positive in $62 \%$ of patients with metastatic disease [24] and $<20 \%$ for mesothelioma [25]. Repeated large-volume thoracentesis increases the yield by $27 \%$ at second aspiration, and a further $5 \%$ at the third [26]. Addition of closed pleural biopsy merely improves the yield by $10 \%$ and it is of little value for tumors confined to the diaphragmatic, visceral or mediastinal pleura [27].

Despite repeated thoracentesis and closed needle biopsy, $20-25 \%$ of pleural effusions remain undiagnosed [28]. The primary advantage of thoracoscopy is to enhance diagnostic capabilities where non-invasive tests fail [29]. Thus, if neoplasm is strongly suspected, diag- nostic sensitivity of thoracoscopic exploration and biopsy approaches $90-100 \%[8-12,14,18]$. Although certain endoscopic characteristics such as nodules, polypoid masses and 'candle wax drops' are suggestive of malignancy in $86 \%$ (fig. 4) [28, 29], early-stage mesothelioma could resemble pleural inflammation (fig. 5). Chrysanthidis and Janssen [30] added autofluorescence to white-light thoracoscopy for the evaluation of 24 patients with exudative pleural effusions. The aims were to determine if the autofluorescence mode could differentiate early malignant lesions from non-specific inflammation; aid in selecting appropriate sites for biopsy, and better delineate tumor margins for more precise staging. Color change from white/pink to red was demonstrated in all cases of malignant pleuritis giving a sensitivity of $100 \%$. These lesions were more easily located and their margins more precisely delineated with autofluorescence thoracoscopy. In 2 cases of chronic pleuritis, color change from white/pink to orange/red was also observed giving a specificity of $75 \%$. Although the authors concluded that there was little value of autofluorescence thoracoscopy in clinical practice since most patients with malignant pleural effusions had extensive pleural involvement which was easy to diagnose with white-light thoracoscopy, the autofluorescence mode might be useful for studying early-stage pleural malignancies [30]. Similar conclusions were derived from a recent study that evaluated narrow band imaging (NBI) technology that was incorporated into the flexiblerigid videopleuroscope (prototype Olympus XLTF 160). NBI technology uses unfiltered narrow bands in the blue $(415 \mathrm{~nm})$ and green $(540 \mathrm{~nm})$ light that coincide with the peak absorption of oxyhemoglobin. By applying these wavelengths, NBI enhances the vascular architecture of tissues. In this study, all patients had malignant involvement of the pleura, of which 9 were mesotheliomas. The authors did not find a difference in diagnostic accuracy between NBI and white-light videopleuroscopy [31]. We also share the same observations in 45 patients with pleural effusions of unclear etiology [unpubl. data]. Thirtytwo patients have pleural metastases, 12 have pulmonary tuberculosis and 1 with chronic pleuritis was followed for 8 months. Although NBI has enhanced the pleural vasculature well, it is difficult to discriminate tumor neovascularization from inflammation based on vascular patterns. In patients with metastatic pleural malignancy, NBI has demarcated tumor margins clearly and aided in the selection of sites for biopsy, however no difference in histological diagnosis is observed between biopsies obtained with white light versus NBI. 
4

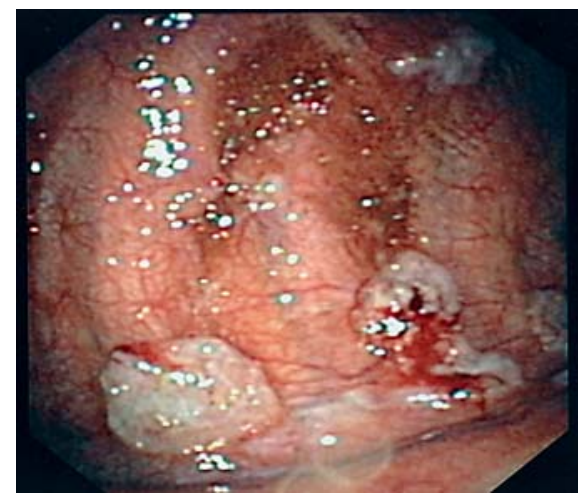

5

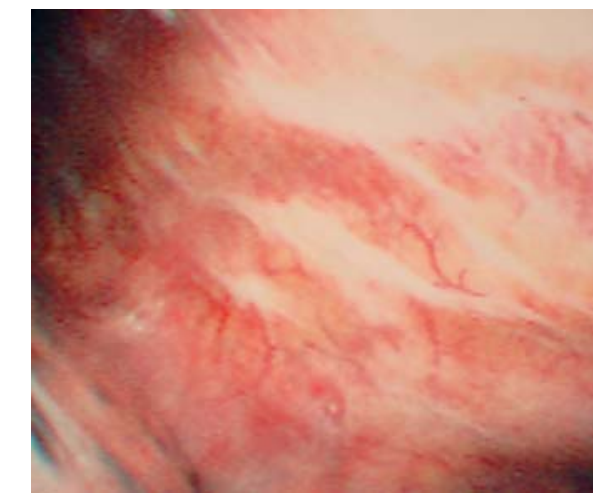

Fig. 4. Polypoid masses, candle wax nodules.

Fig. 5. Pachypleuritis of early mesothelioma.

Table 3. Characteristics suitable for rigid or flexible-rigid thoracoscopy

\begin{tabular}{|c|c|}
\hline Patient, radiological, endoscopic characteristics & Type of procedure \\
\hline $\begin{array}{l}\text { Diagnostic thoracoscopy for indeterminate uncomplicated } \\
\text { pleural effusion where suspicion of mesothelioma is not high }\end{array}$ & $\begin{array}{l}\text { Flexible-rigid thoracoscopy }{ }^{1} \text { (better tolerated) or with rigid tele- } \\
\text { scopes under local anesthesia }\end{array}$ \\
\hline $\begin{array}{l}\text { Trapped lung, radiological thickened pleura, endoscopic } \\
\text { infiltrated pleura }\end{array}$ & $\begin{array}{l}\text { Rigid optical biopsy forceps }{ }^{1} \text {, flexible forceps performing multiple } \\
\text { bites over the same area to obtain specimens of sufficient depth or } \\
\text { IT knife }\end{array}$ \\
\hline Mesothelioma is suspected & Rigid optical biopsy forceps ${ }^{1}$ or IT knife \\
\hline Pleuro-pulmonary adhesions & $\begin{array}{l}\text { Fibrous: rigid optical biopsy forceps }{ }^{1} \text { or flexible-rigid thoracoscopy } \\
\text { with electrocautery accessories } \\
\text { Fibrinous (good alternative): flexible forceps }\end{array}$ \\
\hline Empyema, split pleural sign, loculated pleural effusion & Rigid instruments or converting to thoracotomy for decortication \\
\hline Pneumothorax with bullae or blebs & Rigid instruments (VATS) for staple bullectomy \\
\hline
\end{tabular}

Baas et al. [32] investigated if prior administration of 5-aminolaevulinic acid (ALA) before VATS could lead to improved detection and staging of thoracic malignancy. In this study, the patients were given 5-ALA per oral 3-4 $\mathrm{h}$ before VATS. The pleural cavity was then examined using white light followed by fluorescence thoracoscopy (D light Autofluorescence System, Storz, Tuttlingen, Germany). Tissue sampling of all abnormal areas was preformed, and histological diagnoses were compared against thoracoscopic findings. Fluorescence mode did not demonstrate superior diagnostic accuracy over white light, but led to upstaging in 4 of 15 patients with mesothelioma due to better visualization of visceral pleural lesions that were otherwise undetectable by white light. Several post-operative complications were reported, and these included 1 death from myocardial infarction $72 \mathrm{~h}$ after the procedure; wound infection and pulmonary infection requiring antibiotics, and grade 1 skin burn 28-36 h after 5-ALA administration. The authors concluded that fluorescence thoracoscopy using 5-ALA was feasible with minimal side effects, and could have potential applications in the diagnosis and staging of mesothelioma [32].

\section{Malignant Mesothelioma}

The average survival of a patient diagnosed with malignant mesothelioma is 6-18 months with death from respiratory failure [33]. Malignant mesothelioma is suspected in a patient with a history of asbestos exposure, and characteristic radiographic findings of a pleural effusion without contralateral mediastinal shift. Diagnosis 


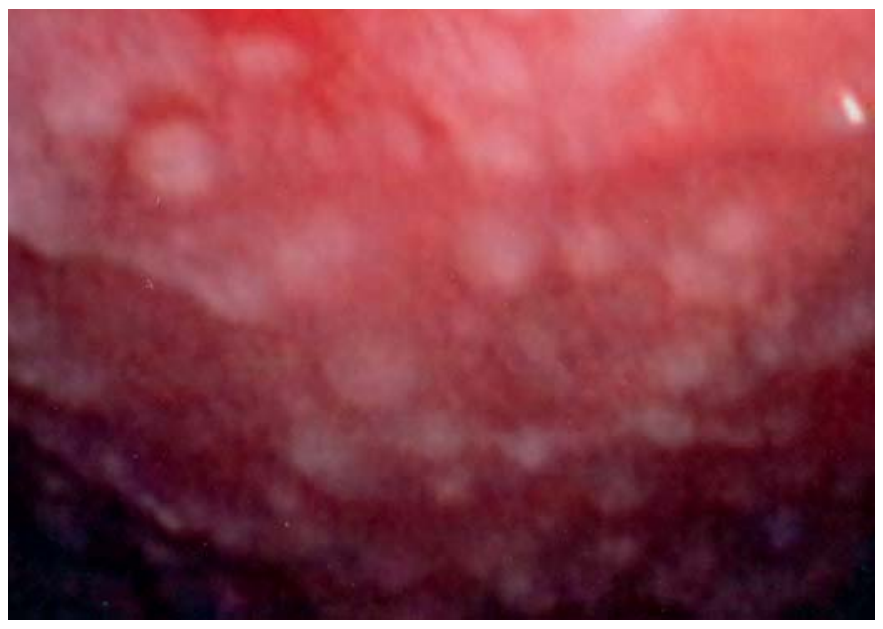

Fig. 6. Sago nodules in TB effusion.

by pleural fluid cytology and closed needle biopsy is difficult, which has prompted some physicians to advocate open biopsy by mini or lateral thoracotomy to obtain specimens of sufficient size and quantity for immunohistochemical stains and electron microscopy [34]. Conventional thoracoscopy is favored over thoracotomy as the pleural specimens obtained with the 5- or 7-mm rigid forceps are comparable with open biopsies [35]. Moreover, it allows staging to be performed in a minimally invasive manner, and fluorescence detection using 5 ALA is a method to improve its staging accuracy [32].

Adequacy of biopsies using the flexible forceps with flexible-rigid pleuroscope is a valid concern. We recommend use of rigid 5-mm optical forceps or IT knife for biopsy in cases where mesothelioma is suspected. Mesothelioma is notorious for seeding biopsy and chest tube sites, thus thoracoscopy and chest tube incisions should be sited to allow excision if subsequent therapeutic resection is performed [36]. Estimates have suggested that only $1-5 \%$ of patients are suitable for curative surgery [37]. In the majority who have advanced disease even at first presentation, aggressive palliation of dyspnea via thoracoscopic-guided drainage and talc pleurodesis, improved pain management, and irradiation of symptomatic metastases that have developed along pleural intervention tracts and incision sites have resulted in effective symptom control [38].

\section{Tuberculous Pleural Effusion}

The average diagnostic yield from closed needle biopsy in tuberculous (TB) pleural effusion is $69 \%$, and a wide range (28-88\%) has been reported (fig. 6) [39]. In a prospective study of $100 \mathrm{~TB}$ effusions in Germany, immediate histological diagnosis was established by thoracoscopy in $94 \%$ compared with $38 \%$ by closed needle biopsy. Positive yield from histology and bacteriological cultures was also found to be higher with thoracoscopic-guided biopsies than with closed needle biopsy and pleural fluid combined [40]. These results were reproduced in a study conducted in a country with high TB prevalence where diagnostic yield from thoracoscopic-guided biopsy was $98 \%$ compared with $80 \%$ by the Abrams needle [41]. Experts recommend thoracentesis and closed needle biopsy if TB pleuritis is strongly suspected in a patient from TB prevalent area, and thoracoscopy reserved for adhesiolysis in loculated effusion or when large quantities of tissue are required for culture in suspected drug-resistant cases [41].

\section{Empyema and Complicated Parapneumonic Effusions}

For pulmonologists intent on performing thoracoscopy for empyema, the procedure should be conducted early in the course of disease where lysis of thin fibrinopurulent adhesions is feasible to facilitate fluid evacuation and lung expandibility [42, 43]. An optimally placed chest tube during thoracoscopy also aids in fluid drainage and further hastens clinical resolution of symptoms. However, when 'split pleural sign' is observed on CT, the radiological sign indicates thick pleural peel, trapped lung or a complicated multiloculated pleural space, which prompts surgical referral for decortication [44].

\section{Pneumothorax}

In spontaneous pneumothorax (SP), thoracoscopy can reveal blebs and bullae, which can be coagulated, and SP recurrence prevented by pleural abrasion or talc pleurodesis [45]. Detection of blebs and bullae is higher with VATS or thoracotomy than thoracoscopy [46], however investigators have not demonstrated better outcome following specific treatment of bullae associated with primary or secondary SP $[47,48]$. This is particularly of relevance to a group of patients with secondary SP from advanced lung disease, who are at higher risk of general anesthesia, VATS or thoracotomy but require interventions to prevent SP recurrence. In these patients, thoracoscopic talc poudrage performed under local anesthesia and conscious sedation has been shown to be an effective therapeutic option [48]. In recurrent primary SP, VATS with staple bullectomy and parietal pleural abrasion, pleurectomy or talc poudrage is preferred $[47,49]$. 


\section{Conclusion}

Thoracoscopy is effective in the evaluation of pleural and pulmonary diseases when routine cytology and closed needle biopsy fail. In many institutions where facilities for thoracoscopy are available, it replaces second-attempt thoracentesis and closed needle biopsy for patients with exudative effusions of unclear etiology. Thoracoscopy also offers the non-surgeon the ability to intervene therapeutically; to break down loculations in early empyemas and complicated parapneumonic effusions, and to perform pleurodesis for recurrent malignant effusions and pneumothoraces. With the introduction of the flexible-rigid pleuroscope, similar in design and handling to the flexible bronchoscope, being compatible with standard light source and video processor available in most bronchoscopy suites, it is conceivable that thoracoscopy will continue to enjoy an expanded interest both as a diagnostic and therapeutic tool.

Although thoracoscopy is generally safe, it is an invasive procedure and to minimize procedure-related complications, pulmonologists intent on thoracoscopy should receive specific training in the techniques and instrumentation. Importantly, he or she should be cognizant of appropriate patient selection, indications and contraindi- cations of thoracoscopy as well as equipped with knowledge and skill to manage complications. A consultative collaboration between the pleuroscopist, primary-care physician, chest radiologist and thoracic surgeon assures that patients undergoing these procedures are assessed from all perspectives.

We are of the opinion that thoracoscopy will play a greater role in the future as more practitioners acquire the skill. The technique is made simpler with the introduction of the flexible-rigid pleuroscope that is similar in design and handling to the flexible bronchoscope, and obviates additional costs by its compatibility with standard equipment found in most endoscopy suites. The flexible-rigid pleuroscope is a significant invention in the history of minimally invasive pleural procedures and we believe it will revolutionize the practice of pulmonary medicine by replacing conventional biopsy methods in the near future [50]. As pleuroscopic technology and techniques continue to evolve, it will pave new inroads into stimulating novel research and directing education, and the current debate should not focus on the time-honored controversy of 'who and where' to perform thoracoscopy but rather 'when and how' to use rigid and flexible-rigid instruments in different clinical scenarios.

\section{References}

-1 McKenna RJ Jr: Thoracoscopic evaluation and treatment of pulmonary disease. Surg Clin North Am 2002;80:1543-1553.

$\checkmark 2$ Yim AP, Lee TW, Izzat MB, et al: Place of video-thoracoscopy in thoracic surgical practice. World J Surg 2001;25:157-161.

$\checkmark 3$ Lee P, Colt HG: Rigid and semi-rigid pleuroscopy: the future is bright. Respirology 2005; 10:418-425

4 Tassi GF, Davies RJ, Noppen M: Advanced techniques in medical thoracoscopy. Eur Respir J 2006;28:1051-1059.

5 Moisiuc FV, Colt HG: Thoracoscopy: origins revisited. Respiration 2007;74:344-355.

6 Jacobaeus HC: Über die Möglichkeit, die Zystoskopie bei Untersuchungen seröser Höhlungen anzuwenden. Münch Med Wochenschr 1910;40:2090-2092.

7 Jacobaeus HC: The practical importance of thoracoscopy in surgery of the chest. Surg Gynecol Obstet 1922;34:289-296.

$\checkmark 8$ Rodriguez-Panadero F, Janssen JP, Astoul P: Thoracoscopy: general overview and place in the diagnosis and management of pleural effusion. Eur Respir J 2006;28:409-421.

-9 Colt HG: Thoracoscopy: window to the pleural space. Chest 1999;107:1409-1415.
10 Tassi G, Marchetti G: Minithoracoscopy: a less invasive approach to thoracoscopy minimally invasive techniques. Chest 2003; 124:1975-1977.

11 Munavvar M, Khan MA, Edwards J, et al: The autoclavable semi-rigid thoracoscope: the way forward in pleural disease? Eur Respir J 2007;29:571-574

12 Lee P, Colt HG: State of the art: pleuroscopy. J Thorac Oncol 2007;2:663-670.

13 Hersh CP, Feller-Kopman D, Wahidi M, et al: Ultrasound guidance for medical thoracoscopy: a novel approach. Respiration 2003;70: 299-301.

14 Mathur P, Astoul P, Boutin C: Medical thoracoscopy. Clin Chest Med 1995;16:479486.

-15 Migliore M, Giuliano R, Aziz T, et al: Fourstep local anesthesia and sedation for thoracoscopic diagnosis and management of pleural diseases. Chest 2002;121:2032-2035.

16 Danby CA, Adebonojo SA, Moritz DM: Video-assisted talc pleurodesis for malignant pleural effusions utilizing local anesthesia and IV sedation. Chest 1998;113:739-742.
17 Lee P, Colt HG: A spray catheter technique for pleural anesthesia: a novel method for pain control before talc poudrage. Anesth Analg 2007;104:198-200.

18 Lee P, Hsu A, Lo C, Colt HG: Prospective evaluation of flex-rigid pleuroscopy for indeterminate pleural effusion: accuracy, safety and outcome. Respirology 2007;12:881-886.

19 Sasada S, Kawahara K, Kusunoki Y, Okamoto N, Iwasaki T, Suzuki H, Kobayashi M, Hirashima T, Matsui K, Ohta $\mathrm{M}$, Miyazawa T: A new electrocautery pleural biopsy technique using an insulated-tip diathermic knife during semirigid pleuroscopy. Surg Endosc 2009;23:1901-1907.

20 Shaw P, Agarwal R: Pleurodesis for malignant pleural effusions. Cochrane Database Syst Rev 2004, CD002916.

21 Viskum K, Enk B: Complications of thoracoscopy (review). Poumon Cœur 1981;37: 25-28.

22 Boutin C, Viallat JR, Cargnino P: La thoracoscopie en 1980. Revue générale. Poumon Cœur 1981;37:11-19.

23 American Thoracic Society: Management of malignant pleural effusions. Am J Respir Crit Care Med 2000;162:1987-2001. 
-24 Hsu C: Cytologic detection of malignancy in pleural effusion: a review of 5,255 samples from 3,811 patients. Diagn Cytopathol 1987; $3: 8-12$.

25 Renshaw AA, Dean BR, Antman KH, Sugarbaker DJ, Cibas ES: The role of cytologic evaluation of pleural fluid in the diagnosis of malignant mesothelioma. Chest 1997;111: 106-109.

-26 Starr RL, Sherman ME: The value of multiple preparations in the diagnosis of malignant pleural effusions: a cost-benefit analysis. Acta Cytol 1991;35:533-537.

-27 Canto A, Ferrer G, Ramagosa V, Moya J, Bernat R: Lung cancer and pleural effusion: clinical significance and study of pleural metastatic locations. Chest 1985;87:649651.

28 Boutin C, Cargnino P, Viallat JR: Thoracoscopy in the early diagnosis of malignant pleural effusions. Endoscopy 1980;12:155160.

-29 Weissberg D, Kaufman M, Zurkowski Z: Pleuroscopy in patients with pleural effusion and pleural masses. Ann Thorac Surg 1980; 29:205-208.

30 Chrysanthidis MG, Janssen JP: Autofluorescence videothoracoscopy in exudative pleural effusions: preliminary results. Eur Respir J 2005;26:989-992.

-31 Schonfeld N, Schwarz C, Kollmeier J, et al: Narrow band imaging (NBI) during medical thoracoscopy: first impressions. J Occup Med Toxicol 2009;4:24-28.
-32 Baas P, Triesscheijn M, Burgers S, van Pel R, Stewart F, Aalders M: Fluorescence detection of pleural malignancies using 5-aminolaevulinic acid. Chest 2006;129:718-724.

33 Legha SS, Muggia FM: Pleural mesothelioma: clinical features and therapeutic implications. Ann Intern Med 1977;87:613-621.

34 Herbert A, Gallagher PJ: Pleural biopsy in the diagnosis of malignant mesothelioma. Thorax 1982;37:816.

35 Boutin C, Rey F: Thoracoscopy in pleural malignant mesothelioma: a prospective study of 188 consecutive patients. 1. Diagnosis. Cancer 1993;72:389-393.

36 Boutin C, Rey F, Viallat JR: Prevention of malignant seeding after invasive diagnostic procedures in patients with pleural mesothelioma: a randomized trial of local therapy. Chest 1995; 108:754-758.

37 Sugarbaker DJ, Garcia JP, Richards WG, et al: Extrapleural pneumonectomy in the multimodality therapy of malignant pleural mesothelioma. Results in 120 consecutive patients. Ann Surg 1996;224:288-294.

38 Parker C, Neville E: Management of malignant mesothelioma. Thorax 2003;58:809813.

39 Mathur PN, Loddenkemper R: Medical thoracoscopy: role in pleural and lung diseases in Beamis JF Jr, Mathur PN (eds): Interventional Pulmonology. New York, McGrawHill, 1999, pp 169-184.

40 Loddenkemper R, Mai J, Scheffeler N, et al: Prospective individual comparison of blind needle biopsy and of thoracoscopy in the diagnosis and differential diagnosis of tuberculous pleurisy. Scand J Respir Dis 1978;102: 196-198.

-41 Diacon AH, Van de Wal BW, Wyser C, et al: Diagnostic tools in tuberculosis pleurisy: a direct comparative study. Eur Respir J 2003; 22:589-591.
42 Cameron RJ: Management of complicated parapneumonic effusions and thoracic empyema. Intern Med J 2002;32:408-414.

43 Colice GL, Curtis A, Deslauriers J, et al: Medical and surgical treatment of parapneumonic effusions: an evidence-based guideline. Chest 2000;18:1158-1171.

44 Heffner JE, Klein JS, Hampson C: Interventional management of pleural infections. Chest 2009; 136:1148-1159.

45 Lee P, Colt HG: Thoracoscopy: an update on therapeutic applications. J Respir Dis 2003; 24:530-536.

46 Schramel FM, Postmus PE, Vanderschueren RG: Current aspects of spontaneous pneumothorax. Eur Respir J 1997;10:1372-1379.

47 Tschopp JM, Boutin C, Astoul P, et al: Talcage by medical thoracoscopy for primary spontaneous pneumothorax is more cost-effective than drainage: a randomized study. Eur Respir J 2002;20:1003-1009.

48 Lee P, Yap WS, Pek WY, et al: An audit of medical thoracoscopy and talc poudrage for pneumothorax prevention in advanced chronic obstructive pulmonary disease. Chest 2004;125:1315-1320.

-49 Baumann MH, Strange C, Heffner JE, et al: Management of spontaneous pneumothorax: an American College of Chest Physicians Delphi Consensus Statement. Chest 2001;119:590-602.

50 Lee P, Colt HG: Steps to flex-rigid pleuroscopy; in Lee P, Colt HG (eds): Flex-Rigid Pleuroscopy, Step by Step. Singapore, CMPMedica, 2005, pp 77-111. 